Int. J. Electrochem. Sci., 14 (2019) $8340-8354$

International Journal of

ELECTROCHEMICAL

SCIENCE

$\underline{\text { www.electrochemsci.org }}$

\title{
The REV-scale Lattice Boltzmann Method Numerical Simulation of Flow and Mass Transfer in Porous Electrode Plate of Zinc-nickel single-flow battery
}

\author{
Yao Shouguang ${ }^{1, *}, W u \mathrm{Hao}^{1}$, Xiao Min ${ }^{1}$, Cheng Jie ${ }^{2}$, Shen Yaju ${ }^{2}$ \\ ${ }^{1}$ Jiangsu University of Science and Technology, Zhenjiang 212003, China \\ ${ }^{2}$ Zhangjiagang Zhidian Fanghua Storage Research Institute, Zhangjiagang 215600, China \\ *E-mail: zjyaosg@126.com
}

doi:10.20964/2019.08.85

Received: 1 April 2019 / Accepted: 21 May 2019 / Published: 30 June 2019

\begin{abstract}
Based on the lattice Boltzmann method, the flow mass transfer process of the electrolyte in the porous cathode of zinc-nickel single-liquid battery in the entire percolation region was numerically simulated from the characterization of the voxel (REV) scale. Firstly, based on the cell structure and the structure characteristics of the battery sintered nickel porous medium, a 2D porous region calculation model is constructed. The average physical quantity of the porous medium is defined by the volume average method on the REV scale, and the LBE model based on the general seepage model is selected. A computational analysis model was established. On this basis, the numerical simulation of the flow mass transfer process inside and on the porous electrode was performed. The change of velocity field and concentration field distribution in the electrode channel of the battery were obtained. Increasing the inlet flow rate of the electrolyte was beneficial to the increase of the percolation intensity in the porous medium. Finally, the percolation velocity was increased. At the same time, the charging density was appropriately increased. Thus, the reaction rate in the electrode was accelerated, and the ion concentration finally reached a stable value. The influence of electrolyte flow rate and constant current charging current density on the electrode reaction in the flow channel needs further exploration.
\end{abstract}

Keywords: Lattice Boltzmann method, REV scale, Porous medium seepage, flow mass transfer

\section{FULL TEXT}

(C) 2019 The Authors. Published by ESG (www.electrochemsci.org). This article is an open access article distributed under the terms and conditions of the Creative Commons Attribution license (http://creativecommons.org/licenses/by/4.0/). 